\title{
Optimisation of Plant-based Milk Formulation using Hazelnut, Sunflower Seed and Pumpkin Seed by Mixture Design
}

\author{
Canan Kuru $^{1, a}$, Ismail Tontul ${ }^{1, b, *}$ \\ ${ }^{1}$ Department of Food Engineering, Faculty of Engineering and Architecture, Necmettin Erbakan University, 42090 Konya, Turkey \\ *Corresponding author
}

\section{A R T I C L E I N F O A B S T R A C T}

Research Article

The preference for plant-based foods has been increased in recent years. Animal milk alternatives, named as plant-based milk, are produced from different oilseeds, nuts and cereals by a series of processing steps. These plant-based milk have different advantages over animal milk such as being lactose and cholesterol-free and having a high content of phenolics, minerals and unsaturated fatty

Received : 09/07/2020

Accepted : 02/09/2020 acids. On the contrary, they generally have a lower content of proteins and low sensorial acceptability. To overcome these disadvantages, an optimisation by mixture design was carried out to produce high-quality plant-based milk in terms of chemical, physical and sensorial properties. The results showed that dry matter $(7.7-11.5 \mathrm{~g} / 100 \mathrm{~mL})$ and ash $(0.11-0.46 \mathrm{~g} / 100 \mathrm{~mL})$ content of the samples increased using a combination of sunflower seeds and pumpkin seeds. Total phenolic

Keywords:

Plant-based milk content and DPPH radical scavenging activity of plant-based milk were governed by the ratio of sunflower seeds. Hazelnut ratio in the samples had a positive impact on protein content (0.17-1.85 $\mathrm{g} / 100 \mathrm{~mL}$ ), whiteness index, serum stability and sensorial properties. The optimum formulation was Whiteness index Sensorial properties Chemical properties Total phenolic content determined as $66.3 \%$ hazelnut, $0 \%$ pumpkin seed and $33.7 \%$ sunflower seed. Verification studies showed a good agreement between theoretical and experimental responses.

\section{Introduction}

In the last decade, the reasons for consumers to prefer food have changed due to increasing health awareness. Consumers have become more interested in products which offer additional health benefits. Moreover, different nutrition trends such as vegetarianism and veganism have become more popular among especially in developed countries (Rincon et al., 2020).

The veganism is the ideology of avoiding the use of all goods produced from animals (Braunsberger and Flamm, 2019). Forgrieve (2018) reported to the vegan percentage in the USA increased to $6 \%$ in 2017 , while it was around $1 \%$ in 2014 . This trend enormously increased the vegan food market, and it was reported as \$3.1 billion in 2017 (Braunsberger and Flamm, 2019). Moreover, the market size is estimated to reach more than $\$ 24$ billion by 2026 by Acumen Research and Consulting. Therefore, many food manufacturers develop and offer alternative foods such as plant-based milk, meat alternative and egg-like products for vegans. Plant-based milk is the fastest growing vegan foods and demand to cow's milk decreased about $5 \%$ in 2016 in USA. In addition, plant-based milk were reported to comprise about $9 \%$ of total milk sales (Braunsberger and Flamm, 2019).

Plant-based milk for vegan nutrition is generally produced by homogenisation of various oilseeds, seeds, legumes and cereals in water (Rincon et al., 2020). For this purpose, hazelnut, peanut, almond, soy, rice, macadamia, oats and cashew are widely used. The production process mainly consists of soaking, grinding, separation, hydrolysis, blanching, thermal processing, homogenisation, and formulation stages (McClements et al., 2019). Plant-based milk is lactose and cholesterol-free, which is the main advantages over animal milk. They are also rich in minerals, phenolic substances, mono and polyunsaturated fatty acids (Sethi et al., 2016). However, they generally have a low content of protein, vitamin $\mathrm{D}$ and some minerals compared to animal milk (ChalupaKrebzdak et al., 2018; Rincon et al., 2020). Moreover, the sensorial acceptability of the plant-based milk is reported to be low in different studies (Mäkinen et al., 2015; Pineli et al., 2015; Rincon et al., 2020). Therefore, additional studies are needed to produce a plant-based milk with high chemical, physical and sensorial properties. 
The nutritional properties of vegan milk depend on the raw material and the processing method. Plant-based milk is generally produced from single raw material and therefore have a lower content of protein, calcium and iron than animal milk. Indeed, Jeske et al. (2017) determined the physicochemical properties of commercial plant-based milk and reported the protein content of the samples as less than $0.5 \%$ except for soy-based milk. Moreover, the usage of a combination of raw materials is an alternative approach to limit the disadvantages of plant-based milk. There are only a few studies conducted to produce plantbased milk using a combination of different raw materials (Sethi et al., 2016). In a study conducted by Deshpande et al. (2008), response surface methodology was employed to optimise chocolate flavoured plant-based milk produced using peanut and soy. The results of the study showed that the optimum formulation was determined to be closer to the maximum limit of soy. In another study, African yam bean and maise (70:30) blends were used in plant-based milk production with high protein content. Kundu et al. (2018) produced a blended plant-based milk using soy and almond at different ratios. They determined the optimum formulation as $60 \%$ almond and $40 \%$ soy. In a recent study, Rincon et al. (2020) produced plant-based milk from chickpea and coconut at different ratios. They determined the optimum ratio of the raw materials as 70:30 according to chemical, physical and sensorial properties.

In the present study, it is aimed to optimise a blended plant-based milk formulation produced using hazelnut, sunflower seed and pumpkin seed by mixture design. The mixture design was employed to achieve a formulation with good chemical and physical properties and sensorial acceptability. For this purpose, chemical (dry matter content, protein content, oil content, ash content, total phenolic content and DPPH radical scavenging activity), physical (whiteness index and serum stability) and sensorial (colour, appearance, taste, flavour, consistency and acceptability) properties of the samples produced at different formulation was characterised and statistically modelled. Then the optimum formulation was calculated and produced for verification studies.

\section{Material and Methods}

\section{Material}

Hazelnut, sunflower seed and pumpkin seed were used as raw materials in plant-based milk production, and all raw materials were bought as dehulled from a local market (Konya, Turkey). These materials were chosen due to their availability, sensorial acceptability and cost. All chemicals used in the analyses were reagent grade and obtained from Sigma (Germany).

Experimental Design and Plant-Based Milk Production

A Simplex Centroid mixture design was used to determine the optimum formulation of plant-based milk. For this purpose, an experimental design was generated using Design Expert 10 (Stat-Ease, MN, USA), and all raw materials were tested in the range of $0 \%$ and $100 \%$. As can be seen in Table 1, 14 formulations (with four replication) was produced. For this purpose, $200 \mathrm{~g}$ of raw materials, according to the experimental design, hydrated in $400 \mathrm{~mL}$ of distilled water at $+4^{\circ} \mathrm{C}$ for overnight. Then, the mixture was drained, $1000 \mathrm{~mL}$ distilled water was added on the nuts and blended using a blender (Arzum, Turkey) at $20000 \mathrm{rpm}$ for $3 \mathrm{~min}$. The blended mixture was filtered from a threelayer of cheesecloth and bottled (Bernat et al., 2015). Finally, the plant-based milk was pasteurised at $85^{\circ} \mathrm{C}$ for $10 \mathrm{~min}$. This conditions were decided according to the preliminary experiments. The milk was stored at $+4^{\circ} \mathrm{C}$ until analysis which was completed in a week.

Table 1. Experimental design

\begin{tabular}{c|rcr}
\hline Run & Sunflower seed $(\%)$ & Pumpkin seed $(\%)$ & Hazelnut $(\%)$ \\
\hline 1 & 33.33 & 33.33 & 33.33 \\
2 & 0.00 & 50.00 & 50.00 \\
3 & 0.00 & 100.00 & 0.00 \\
4 & 16.67 & 16.67 & 66.67 \\
5 & 0.00 & 100.00 & 0.00 \\
6 & 50.00 & 0.00 & 50.00 \\
7 & 100.00 & 0.00 & 0.00 \\
8 & 100.00 & 0.00 & 0.00 \\
9 & 16.67 & 66.67 & 16.67 \\
10 & 66.67 & 16.67 & 16.67 \\
11 & 50.00 & 50.00 & 0.00 \\
12 & 50.00 & 50.00 & 0.00 \\
13 & 0.00 & 0.00 & 100.00 \\
14 & 0.00 & 0.00 & 100.00
\end{tabular}

\section{Analyses}

\section{Chemical properties}

Dry matter, protein content, oil content and ash content of the plant-based milk were determined according to the AOAC methods. For the determination of the total phenolic content and DPPH radical scavenging activity of the plant-based milk, an ethanolic extract was prepared by the method performed by Lai et al. (2013) with slight modification. Briefly, dried plant-based milk (at $70^{\circ} \mathrm{C}$ until constant weight) which was defatted using hexane extraction. $18 \mathrm{~mL}$ of aqueous ethanol $(80 \%)$ was added onto $2 \mathrm{~g}$ of defatted sample and homogenised. Then, it was held in a water bath adjusted to $40^{\circ} \mathrm{C}$ for $3 \mathrm{~h}$ and filtered from filter paper. The total phenolic content by FolinCioceltau procedure and DPPH radical scavenging activity of the plant-based milk were determined according to Eyiz et al. (2020). 


\section{Physical properties}

For the determination of serum stability, $40 \mathrm{~g}$ of milk sample was transferred into a tube and centrifuged at 220 $\mathrm{g}$ for $10 \mathrm{~min}$ at $4^{\circ} \mathrm{C}$ (Jeske et al., 2017). The stability was evaluated visually in the range of 1 (total separation) and 10 (no separation) by a panel.

Whiteness index of the plant-based milk was determined by the method performed by Jeske et al. (2018).

Sensorial properties

The sensorial properties of the samples were analysed using a 9-point hedonic scale test. $20 \mathrm{~mL}$ of refrigerated samples coded with a three-digit code and presented under white light. The sensorial attributes of products, namely colour, appearance, taste, flavour, consistency and acceptability were evaluated by ten semi-trained panellists who are graduate students of Department of Food Engineering, Necmettin Erbakan University (Jeske et al., 2018).

\section{Statistical Analyses}

The optimum formulation was determined using the mixture design. All responses were analysed using linear, quadratic and cubic models, and the most suitable model was decided by p-value, lack of fit test and regression coefficient. Insignificant terms were reduced to increase the accuracy of the model. The optimum formulation was calculated using the desirability function (Tontul and Topuz, 2018). The optimum formulation was produced in three replicate, and the theoretical and experimental responses were compared according to the \% error, which was calculated using Excel 2018 (Microsoft, USA).

\section{Results and discussion}

\section{Chemical Properties}

The dry matter content of plant-based milk was determined in the range of 7.7-11.5 g/100 mL (Table 2), and the quadratic model was determined to be the suitable model (Table 3). While linear terms were found to be ineffective on dry matter content, sunflower seed and pumpkin seed interaction had a significant effect on dry matter content of plant-based milk. The lowest amount of dry matter was determined in $100 \%$ of either sunflower seed or pumpkin seed. However, their combined usage increased the dry matter content (Figure 1a). Brix of the peanut-based beverages was reported between 13.7 and 15.8, which is higher than the present study (Gama et al., 2019). In another study, dry matter content of hazelnut milk was determined as $17.6 \mathrm{~g} / 100 \mathrm{~g}$ (Naziri et al., 2017). On the contrary Bernat et al. (2015) reported much lower dry matter content in almond $(6.6 \mathrm{~g} / 100 \mathrm{~g})$ and hazelnut milk $(5.3 \mathrm{~g} / 100 \mathrm{~g})$. Therefore, it can be deduced that the dry matter content of the plant-based milk highly depends on the raw material concentration in the production process.

The protein content of the samples modelled using a linear model and was ranged between $0.17 \mathrm{~g} / 100 \mathrm{~mL}$ and $1.85 \mathrm{~g} / 100 \mathrm{~mL}$ (Table 2). As it can be seen in Figure 1b, increasing the hazelnut concentration in the formulation resulted in a higher content of proteins in plant-based milk. These could be related to the soluble protein content of the raw materials.

Table 2. Chemical, physical and sensorial results according to the formulation

\begin{tabular}{|c|c|c|c|c|c|c|c|}
\hline Run & $\begin{array}{c}\text { Dry matter content } \\
(\mathrm{g} / 100 \mathrm{~mL})\end{array}$ & $\begin{array}{l}\text { Protein content } \\
(\mathrm{g} / 100 \mathrm{~mL})\end{array}$ & $\begin{array}{l}\text { Oil content } \\
(\mathrm{g} / 100 \mathrm{~mL})\end{array}$ & $\begin{array}{l}\text { Ash content } \\
(\mathrm{g} / 100 \mathrm{~mL})\end{array}$ & $\begin{array}{c}\text { Total phenolic content } \\
(\mathrm{mg} \text { GAE/L) }\end{array}$ & $\begin{array}{c}\text { Sensorial } \\
\text { appearance }\end{array}$ & $\begin{array}{l}\text { Whiteness } \\
\text { index }\end{array}$ \\
\hline 1 & $11.2 \pm 0.1$ & $1.03 \pm 0.01$ & $1.41 \pm 0.00$ & $0.37 \pm 0.02$ & $1871.1 \pm 1.5$ & $4.9 \pm 2.2$ & $74.0 \pm 0.1$ \\
\hline 2 & $9.6 \pm 0.1$ & $0.51 \pm 0.01$ & $1.13 \pm 0.04$ & $0.11 \pm 0.06$ & $168.9 \pm 4.5$ & $5.5 \pm 2.5$ & $76.2 \pm 0.9$ \\
\hline 3 & $9.3 \pm 0.0$ & $0.34 \pm 0.01$ & $1.18 \pm 0.06$ & $0.34 \pm 0.02$ & $423.2 \pm 9.0$ & $5.2 \pm 1.9$ & $75.0 \pm 0.1$ \\
\hline 4 & $10.3 \pm 0.0$ & $1.21 \pm 0.04$ & $1.17 \pm 0.13$ & $0.22 \pm 0.01$ & $1238.1 \pm 57.2$ & $6.6 \pm 2.1$ & $79.1 \pm 0.1$ \\
\hline 5 & $7.7 \pm 0.0$ & $0.17 \pm 0.01$ & $0.91 \pm 0.03$ & $0.23 \pm 0.04$ & $212.6 \pm 18.1$ & $6.0 \pm 2.4$ & $76.5 \pm 0.2$ \\
\hline 6 & $10.4 \pm 0.0$ & $0.99 \pm 0.01$ & $1.12 \pm 0.11$ & $0.23 \pm 0.00$ & $1587.0 \pm 12.0$ & $5.6 \pm 1.8$ & $76.9 \pm 0.2$ \\
\hline 7 & $8.3 \pm 0.0$ & $0.99 \pm 0.01$ & $1.08 \pm 0.05$ & $0.25 \pm 0.00$ & $3226.0 \pm 4.5$ & $5.6 \pm 1.8$ & $72.2 \pm 0.3$ \\
\hline 8 & $8.2 \pm 0.1$ & $0.84 \pm 0.01$ & $0.95 \pm 0.07$ & $0.25 \pm 0.00$ & $2827.0 \pm 63.2$ & $4.4 \pm 2.0$ & $72.2 \pm 0.2$ \\
\hline 9 & $8.8 \pm 0.2$ & $0.27 \pm 0.01$ & $0.74 \pm 0.20$ & $0.30 \pm 0.02$ & $649.8 \pm 16.5$ & $5.1 \pm 2.4$ & $76.8 \pm 0.4$ \\
\hline 10 & $9.9 \pm 0.1$ & $0.75 \pm 0.02$ & $1.05 \pm 0.06$ & $0.32 \pm 0.00$ & $2144.0 \pm 0.0$ & $5.0 \pm 1.9$ & $72.8 \pm 0.4$ \\
\hline 11 & $11.3 \pm 0.0$ & $0.57 \pm 0.03$ & $1.20 \pm 0.11$ & $0.46 \pm 0.01$ & $1684.5 \pm 9.0$ & $4.6 \pm 1.6$ & $72.8 \pm 0.3$ \\
\hline 12 & $11.5 \pm 0.1$ & $0.93 \pm 0.00$ & $1.40 \pm 0.17$ & $0.46 \pm 0.02$ & $1537.7 \pm 45.1$ & $4.4 \pm 2.2$ & $71.8 \pm 0.1$ \\
\hline 13 & $10.0 \pm 0.0$ & $1.85 \pm 0.00$ & $1.31 \pm 0.04$ & $0.18 \pm 0.00$ & $833.8 \pm 0.0$ & $8.5 \pm 1.0$ & $81.5 \pm 1.6$ \\
\hline 14 & $10.1 \pm 0.0$ & $1.66 \pm 0.16$ & $1.35 \pm 0.23$ & $0.19 \pm 0.02$ & $1174.3 \pm 469.4$ & $8.6 \pm 0.5$ & $82.4 \pm 0.4$ \\
\hline Run & $\begin{array}{c}\text { Serum } \\
\text { stability }\end{array}$ & $\begin{array}{c}\text { Sensorial } \\
\text { colour }\end{array}$ & $\begin{array}{l}\text { Sensorial } \\
\text { flavour }\end{array}$ & $\begin{array}{c}\text { Sensorial } \\
\text { taste }\end{array}$ & $\begin{array}{l}\text { DPPH radical scavenging } \\
\text { activity (mg TE/L) }\end{array}$ & $\begin{array}{c}\text { Sensorial } \\
\text { consistency }\end{array}$ & $\begin{array}{c}\text { Sensorial } \\
\text { acceptability }\end{array}$ \\
\hline 1 & $3.5 \pm 0.7$ & $6.0 \pm 1.5$ & $5.3 \pm 2.4$ & $5.1 \pm 2.4$ & $1992.6 \pm 13.7$ & $5.0 \pm 2.4$ & $5.7 \pm 2.4$ \\
\hline 2 & $9.0 \pm 0.0$ & $5.5 \pm 2.2$ & $6.1 \pm 2.4$ & $5.6 \pm 2.4$ & $81.3 \pm 6.8$ & $5.7 \pm 2.2$ & $5.4 \pm 2.3$ \\
\hline 3 & $1.0 \pm 0.0$ & $4.8 \pm 2.1$ & $4.5 \pm 3.1$ & $4.5 \pm 2.5$ & $192.6 \pm 0.0$ & $5.7 \pm 2.2$ & $4.7 \pm 2.2$ \\
\hline 4 & $7.5 \pm 0.7$ & $6.4 \pm 2.1$ & $6.3 \pm 1.8$ & $5.7 \pm 1.9$ & $986.1 \pm 123.2$ & $6.3 \pm 2.4$ & $6.5 \pm 2.0$ \\
\hline 5 & $10.0 \pm 0.0$ & $5.0 \pm 2.5$ & $6.1 \pm 2.2$ & $5.4 \pm 1.9$ & $95.8 \pm 27.4$ & $6.8 \pm 2.1$ & $5.5 \pm 2.3$ \\
\hline 6 & $6.5 \pm 0.7$ & $7.0 \pm 2.2$ & $6.5 \pm 2.2$ & $6.2 \pm 2.6$ & $2176.5 \pm 164.2$ & $5.7 \pm 2.8$ & $6.4 \pm 2.4$ \\
\hline 7 & $1.5 \pm 0.7$ & $6.4 \pm 1.6$ & $6.1 \pm 2.0$ & $5.3 \pm 2.1$ & $5587.7 \pm 239.5$ & $6.2 \pm 1.8$ & $5.6 \pm 2.1$ \\
\hline 8 & $1.0 \pm 0.0$ & $5.5 \pm 2.3$ & $6.1 \pm 2.1$ & $5.0 \pm 2.3$ & $4852.3 \pm 171.1$ & $5.0 \pm 2.1$ & $5.1 \pm 2.3$ \\
\hline 9 & $10.0 \pm 0.0$ & $4.8 \pm 2.1$ & $5.6 \pm 2.2$ & $5.5 \pm 1.9$ & $739.4 \pm 6.8$ & $6.8 \pm 1.8$ & $5.5 \pm 2.0$ \\
\hline 10 & $2.0 \pm 0.0$ & $5.5 \pm 2.0$ & $5.8 \pm 2.3$ & $5.2 \pm 2.0$ & $3560.3 \pm 232.7$ & $4.6 \pm 2.1$ & $5.3 \pm 2.5$ \\
\hline 11 & $9.0 \pm 0.0$ & $4.5 \pm 2.0$ & $5.6 \pm 2.2$ & $4.2 \pm 2.1$ & $3095.8 \pm 177.9$ & $4.2 \pm 2.5$ & $4.5 \pm 2.0$ \\
\hline 12 & $1.0 \pm 0.0$ & $4.3 \pm 2.3$ & $5.7 \pm 2.3$ & $4.4 \pm 2.5$ & $2428.1 \pm 54.7$ & $4.6 \pm 2.7$ & $5.1 \pm 2.6$ \\
\hline 13 & $10.0 \pm 0.0$ & $8.5 \pm 0.7$ & $7.9 \pm 1.0$ & $7.7 \pm 1.3$ & $105.5 \pm 41.1$ & $7.5 \pm 2.5$ & $7.9 \pm 1.3$ \\
\hline 14 & $9.5 \pm 0.7$ & $8.5 \pm 0.7$ & $7.8 \pm 0.9$ & $8.6 \pm 0.5$ & $105.5 \pm 13.7$ & $7.4 \pm 2.0$ & $7.7 \pm 1.5$ \\
\hline
\end{tabular}

mean \pm std deviation 
Table 3. ANOVA results for each response

\begin{tabular}{l|cccccccc}
\hline \multirow{2}{*}{$\mathrm{V}$} & \multicolumn{2}{c}{ Dry matter content } & Protein content & \multicolumn{2}{c}{ Oil content } & \multicolumn{2}{c}{ Ash content } & \multicolumn{2}{c}{ Total phenolics } \\
content
\end{tabular}

V: Variable, LM: Linear mixture, LF: Lack of fit, ${ }^{*} \mathrm{P}<0.05, \mathrm{P}<0.01$, ns: not significant, A: Sunflower seed, B: pumpkin seed, C: hazelnut

Scholz-Ahrens et al. (2020) reported the protein content of various commercial plant-based milk as $0.3-1.6 \mathrm{~g} / 100 \mathrm{~g}$. Besides, the protein content of various commercial plantbased milk was reported in the range of $0.07-3.70 \mathrm{~g} / 100 \mathrm{~g}$ (Jeske et al., 2017). The results of the present study were consistent with the literature. However, the protein content of hazelnut was reported to be lower $(0.4-0.6 \mathrm{~g} / 100 \mathrm{~g})$ than the present study $(1.7-1.8 \mathrm{~g} / 100 \mathrm{~mL})$. The difference between raw material concentration and production process (especially homogenisation step). Indeed, Gul et al. (2017) reported a significant increase in protein content of hazelnut milk with a rise in homogenisation pressure.

The oil content of the plant-based milk samples determined in a narrow range $(0.74-1.41 \mathrm{~g} / 100 \mathrm{~mL})$ and did not change significantly based on the formulation. Generally, plant based milk contains lower oil content than animal milk $(\sim 3 \mathrm{~g} / 100 \mathrm{~mL})$. Indeed Jeske et al. (2017) reported the oil content of commercial plant based milks in the range of $0.84-4.40 \mathrm{~g} / 100 \mathrm{~g}$. The difference between result could be related to the other ingredients used in the commercial products. All raw materials have a high content of oil, and therefore, oil content of the plant-based milk did not show a significant difference. Indeed, according to the Turkish National Food Composition Database (TURKOMP), oil content of sunflower seeds, pumpkin seeds, hazelnut were $52 \mathrm{~g} / 100 \mathrm{~g}, 50 \mathrm{~g} / 100 \mathrm{~g}$ and 60 $\mathrm{g} / 100 \mathrm{~g}$, respectively (Anonymous, 2020). Therefore, similar fat content was observed in plant-based milk.

Ash content of samples was ranged in $0.11 \mathrm{~g} / 100 \mathrm{~mL}$ and $0.46 \mathrm{~g} / 100 \mathrm{~mL}$ (Table 2). In a previous study, the ash content of different commercial plant-based milk was reported as $0.1-1.0 \mathrm{~g} / 100 \mathrm{~g}$ (Jeske et al., 2017). The result of the present study was consistent with this data. A quadratic model was used to predict the ash content of the samples, and all terms except sunflower seed and hazelnut interaction showed a significant effect on the ash content (Table 3). The highest ash content was determined in plantbased milk produced by sunflower seed and pumpkin seed mixtures, while the lowest ash content was observed in the milk produced by $100 \%$ of hazelnut (Figure 1c). In a study on ash content of different nuts sold in Korea, pumpkin seed had the highest (5.5\%) content of ash which was followed by sunflower seed (3.3\%). The ash content of pumpkin seed, sunflower seed and hazelnut according to TURKOMP is $3.58,3.53$ and 2.28 , respectively. Therefore, hazelnut milk had the lowest ash content (Anonymous, 2020).

Only linear terms were found to be effective on the total phenolic content of the milk (Table 3), which was determined in the range of 168.9 and $3226.0 \mathrm{mg} \mathrm{GAE} / \mathrm{kg}$ dm. Atalar et al. (2019) reported the total content of hazelnut milk in the range of $150.7-178.8 \mathrm{mg} / \mathrm{kg}$, which is similar to the present study when evaluated on dry basis. Figure 1d shows that milk produced using a high ratio of sunflower seed had the highest content of total phenolics which was followed by those of hazelnut and pumpkin seed, respectively. In a previous study on roasted Turkish nuts, sunflower seeds similarly reported having the highest content of total phenolics with $1021.5 \mathrm{mg}$ GAE/100 g which was much higher than those of hazelnut $(138.5 \mathrm{mg}$ GAE/100 g) and pumpkin seeds (37.2 mg GAE/100 g) (Aysun and Sayaslan, 2019).

DPPH radical scavenging activity of plant-based milk was ranged in $81.3-5587.7 \mathrm{mg} \mathrm{TE} / \mathrm{kg} \mathrm{dm}$. Very high regression coefficients were calculated for the linear model. The highest DPPH radical scavenging activity was determined in the plant-based milk sample produced using $100 \%$ of sunflower seed (Figure 1e). 

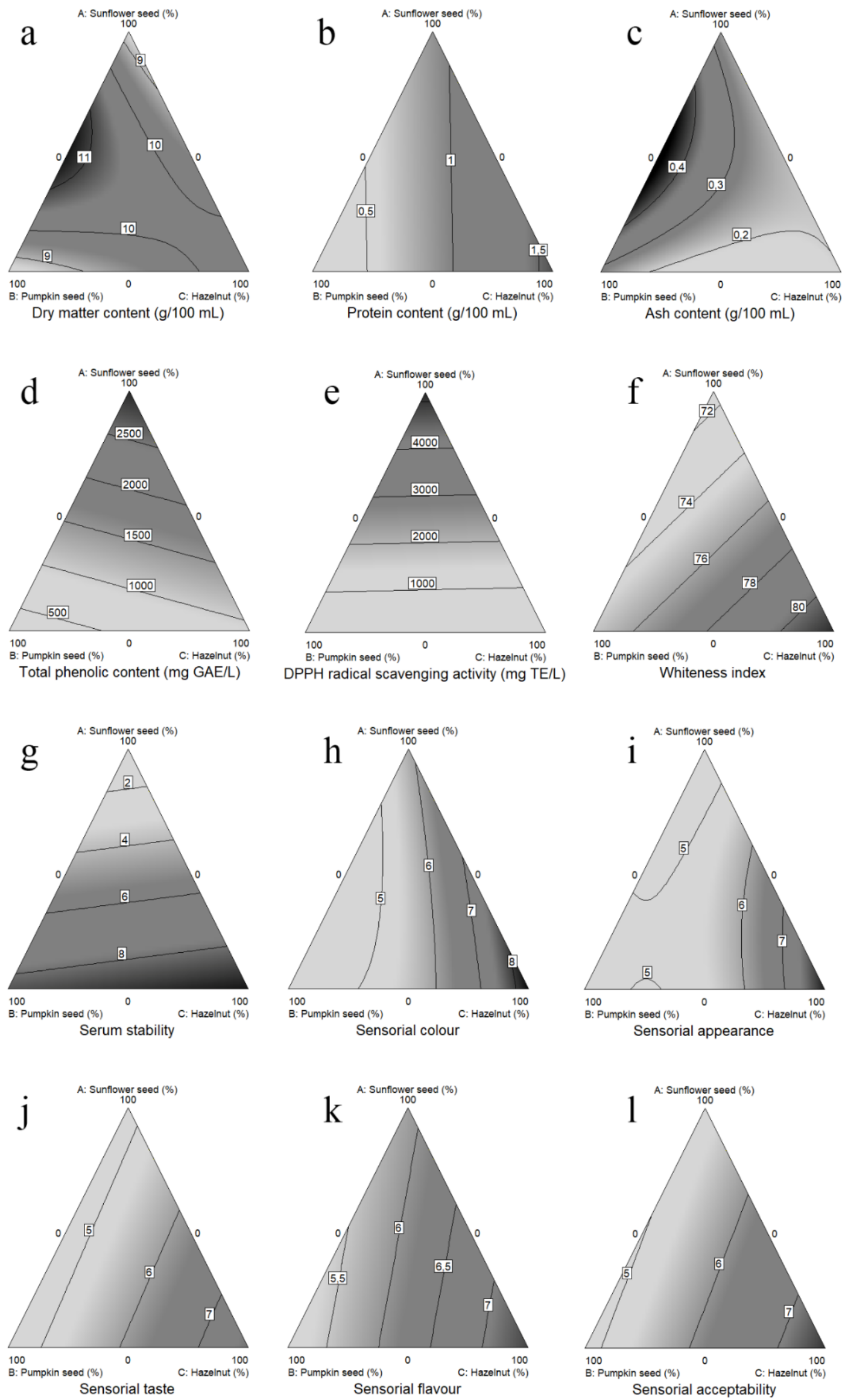

Figure 1. Contour plots of (a) dry matter content, (b) protein content, (c) ash content, (d) total phenolic content, (e) DPPH radical scavenging activity, (f) whiteness index, (g) serum stability, (h) sensorial colour, (i) sensorial appearance,

(j) sensorial taste, (k) sensorial flavour and (l) sensorial acceptability of plant milks according to formulation 
Table 4. Theoretical and experimental results obtained using optimum formulation

\begin{tabular}{l|ccc}
\multicolumn{1}{c}{ Parameters } & Theoretical response & Experimental response* & \% Error \\
\hline Dry matter content $(\mathrm{g} / 100 \mathrm{~mL})$ & 9.8 & $10.1 \pm 0.1$ & 3.1 \\
Protein content $(\mathrm{g} / 100 \mathrm{~mL})$ & 1.35 & $1.34 \pm 0.4$ & 1.0 \\
Ash content $(\mathrm{g} / 100 \mathrm{~mL})$ & 0.21 & $0.21 \pm 0.01$ & 0.6 \\
Total phenolic content $(\mathrm{mg} \mathrm{GAE} / \mathrm{L})$ & 1610.8 & $1618.8 \pm 40.5$ & 0.5 \\
DPPH radical scavenging activity $(\mathrm{mg} \mathrm{TE} / \mathrm{L})$ & 1775.7 & $1694.5 \pm 70.7$ & 4.6 \\
Whiteness index & 78.1 & $79.3 \pm 0.1$ & 1.6 \\
Serum stability & 6.6 & $6.5 \pm 0.7$ & 1.5 \\
Sensorial colour & 7.5 & $7.6 \pm 0.1$ & 0.8 \\
Sensorial appearance & 7.0 & $7.6 \pm 0.2$ & 8.2 \\
Sensorial taste & 6.7 & $7.5 \pm 0.2$ & 12.4 \\
Sensorial flavour & 6.9 & $7.8 \pm 0.2$ & 12.8 \\
Sensorial acceptability & 6.7 & $7.8 \pm 0.4$ & 15.9 \\
\hline Desirability & & 0.538 & \\
\hline
\end{tabular}

* mean \pm std deviation of 3 replicates

In contrast, pumpkin seed and hazelnut milk had similar DPPH radical scavenging activity. Similar results were also reported for antioxidant activity of roasted nuts determined by TEAC and FRAP (Aysun and Sayaslan, 2019). A clear correlation between total phenolic content and antioxidant activity was observed in the present study. This phenomenon was expected since plant phenolics generally have high antioxidant capacity (Dai and Mumper, 2010). As stated above higher phenolic content of sunflower seeds provided higher antioxidant activity in the final milks.

\section{Physical Properties}

Plant-based milk samples produced using different sunflower, hazelnut and pumpkinseed ratios had higher whiteness index than 71.8 (Table 2). Jeske et al. (2017) reported the whiteness index of commercial almond (Alpro and Provamel), soya (Alpro), and quinoa (EcoMil) milk as higher than 71.3. On the contrary thy reported hazelnut milk (Alpro) as 56.3. Indeed, much higher whiteness index (>80) was reported by Bernat et al. (2015). The differences of whiteness index results could be related to the removing of hazelnut skin and other ingredients. A linear model was predicted whiteness index of plant-based milk with insignificant lack of fit and high regression coefficients (Table 3). As expected, increasing the hazelnut concentration resulted in higher whiteness index due to the natural colour of raw material (Figure 1f). On the other hand, sunflower seed concentration negatively affected the whiteness index by decreasing the $\mathrm{L}^{*}$ value of the plantbased milk.

Serum stability is one of the most critical parameters of plant-based milk that affects the marketability of the product. As it can be seen in Table 2, it changed between no serum separation and total serum separation. A linear model was determined to be used to predict serum stability of the plant-based milk. The contour plot showed that while hazelnut and pumpkin seed provided high serum stability, increasing the ratio of sunflower seed in formulation decreased the serum stability (Figure 1g). Therefore, the formulation had an essential effect on the serum stability of plant-based milk. Rincon et al. (2020) produced plantbased milk using different ratios of chickpea and coconut and determined physical stability. They determined that increasing the proportion of coconut in the milk sample was increased physical stability. These results of the present study suggested that extracted proteins from hazelnut and pumpkin seed acted as stabilisation agent during plant-based milk production. On the other hand, sunflower seed seems to lack of interfacial agent, therefore, exposed to total serum separation. Another reason for the low stability of the sunflower seed milk could be related to denser and larger particles in this sample (Cruz et al., 2007; Jeske et al., 2017).

\section{Sensorial Properties}

Sensorial properties of the plant-based milk were evaluated according to colour, appearance, taste, flavour, consistency and general acceptability. All sensorial properties, except consistency, were significantly changed according to the formulation (Table 3). Although the linear model was found to be significant at $\mathrm{p}<0.05$ level for sensorial consistency, the regression coefficients were low. While colour values were modelled using the quadratic model, other sensorial responses were predicted using a linear model.

All sensorial properties showed a similar pattern according to the formulation (Figure 1h-l). Indeed, increasing hazelnut concentration in plant-based milk formulation provided the highest sensorial scoring $(>7)$. This finding could be related to the higher whiteness and mild taste of the plant-based milk obtained at $100 \%$ hazelnut since the consumers are expected the milk as white as possible. Previous studies on sensorial evaluation showed that overall likeness of plant-based milk is generally too low. Mäkinen et al. (2015) reported the overall ratings of plant-based milk produced from soy, oat, quinoa and rice were smaller than five which corresponds "neither like or dislike". Similar results were also reported for quinoa milk as 4.4 (Pineli et al., 2015). The produced milk in the present study had higher sensorial ratings compared to the literature. Pumpkin seed $(100 \%)$ had the lowest sensorial scoring in colour, flavour and acceptability. It is believed the increasing greenness of the plant-based milk due to chlorophyll content of pumpkin seed caused the decrease of the sensorial properties in pumpkin seed rich milk. Moreover, plant-based milk produced using high ratio of sunflower seed had to lowest sensorial appearance scoring probably because of the partial serum separation during sensorial panel. In a previous study on plant-based milk production using coconut and chickpea at different ratios, sensorial 
properties were determined based on overall, colour, odour and taste. All properties showed similar patterns according to the formulation as determined in the present study. The most acceptable formulation was determined as $50 \%$ of chickpea and $50 \%$ of coconut (Rincon et al., 2020).

\section{Optimisation and Verification}

The optimum formulation was calculated using 12 responses that can be modelled statistically. The formulation that maximises all responses were evaluated as the optimum formulation. The calculations according to the desirability function yielded that the formulation that maximises all responses simultaneously was $66.3 \%$ hazelnut, $0 \%$ pumpkin seed and $33.7 \%$ sunflower seed. Using this formulation, three replicated plant-based milk was produced, and experimental responses were obtained (Table 4). Verification studies showed high similarity (\% error <5) in dry matter content, protein content, ash content, total phenolic content, DPPH radical scavenging activity, whiteness index, serum stability and sensorial colour values. However, the error percent was higher in other sensorial parameters than colour. The fact that the plant-based milk produced with the optimum formulation scores high in terms of all sensorial values than theoretical responses in the sensory panel shows that the study has achieved its purpose.

\section{Conclusion}

Plant-based milk formulation was optimised using mixture design for the first time in the present study. While ash content, sensorial colour and sensorial appearance of the plant-based milk can be predicted by the quadratic model, other responses that can be statistically modelled was affected by the linear terms. The protein content of the plant-based milk was governed by the hazelnut ratio in the formulation. The oil content of the sample did not show significant variation based on the formulation, probably because of the similar oil content of the raw materials. Whiteness index and serum stability of the plant milk produced only using hazelnut was determined to be higher among the tested samples. This phenomenon could be related to the colour of the raw material and extracted proteins that have interfacial properties. All sensorial properties showed a similar pattern and increasing hazelnut concentration in the plant-based milk formulation provided the highest sensorial scorings. The optimum formulation was determined as $66.3 \%$ hazelnut, $0 \%$ pumpkin seed and $33.7 \%$ sunflower seed according to desirability function. Verification studies showed high accordance in theoretical and experimental values of chemical and physical properties. However, higher sensorial scorings were determined in experimental studies. Overall, plant-based milk that has good chemical, physical and sensorial properties was developed in the present study.

\section{Conflict of Interest}

The authors have no conflict of interest to declare

\section{References}

Anonymous 2020. Turkish National Food Composition Database, http://www.turkomp.gov.tr/ Accessed on 01.05.2020.
Atalar I, Gul O, Saricaoglu FT, Besir A, Gul LB, Yazici F 2019. Influence of thermosonication (TS) process on the quality parameters of high pressure homogenized hazelnut milk from hazelnut oil by-products. J. Food Sci. Tech., 56: 14051415.10.1007/s13197-019-03619-7

Aysun O, Sayaslan A 2019. Antioxidant Properties of Roasted Whole-Grain, Oilseed and Nut Snacks and Effect of Roasting Process on These Properties. Akademik Gida, 17: 149-156

Bernat N, Chafer M, Rodríguez-García J, Chiralt A, GonzálezMartínez C 2015. Effect of high pressure homogenisation and heat treatment on physical properties and stability of almond and hazelnut milks. LWT, 62: 488-496

Braunsberger K, Flamm RO 2019. The Case of the Ethical Vegan: Motivations Matter When Researching Dietary and Lifestyle Choices 1. J. Manag. Issues, 31: 228-222

Chalupa-Krebzdak S, Long CJ, Bohrer BM 2018. Nutrient density and nutritional value of milk and plant-based milk alternatives. Int. Dairy J., 87: 8492.10.1016/j.idairyj.2018.07.018

Cruz N, Capellas M, Hernández M, Trujillo AJ, Guamis B, Ferragut V 2007. Ultra high pressure homogenization of soymilk: Microbiological, physicochemical and microstructural characteristics. Food Res. Int., 40: 725-732

Dai J, Mumper RJ 2010. Plant phenolics: extraction, analysis and their antioxidant and anticancer properties. Molecules, 15: 7313-7352

Deshpande RP, Chinnan MS, McWatters KH 2008. Optimization of a chocolate-flavored, peanut-soy beverage using response surface methodology (RSM) as applied to consumer acceptability data. LWT, 41: 1485-1492

Eyiz V, Tontul I, Turker S 2020. Optimization of green extraction of phytochemicals from red grape pomace by homogenizer assisted extraction. J. Food Meas. Charact., 14: 3947.10.1007/s11694-019-00265-7

Forgrieve J 2018. The growing acceptance of veganism. Forbes, https://www.forbes.com/sites/janetforgrieve/2018/11/02/pict uring-a-kindler-gentler-world-vegan-month:

Gama AP, Hung Y-C, Adhikari K 2019. Optimization of emulsifier and stabilizer concentrations in a model Peanut-Based beverage system: a mixture design approach. Foods, 8: 116

Gul O, Saricaoglu FT, Mortas M, Atalar I, Yazici F 2017. Effect of high pressure homogenization (HPH) on microstructure and rheological properties of hazelnut milk. Innov. Food Sci. Emerg. Tech., 41: 411-420

Jeske S, Zannini E, Arendt EK 2017. Evaluation of Physicochemical and Glycaemic Properties of Commercial Plant-Based Milk Substitutes. Plant Food. Hum. Nutr., 72: 26-33.10.1007/s11130-016-0583-0

Jeske S, Zannini E, Lynch KM, Coffey A, Arendt EK 2018. Polyol-producing lactic acid bacteria isolated from sourdough and their application to reduce sugar in a quinoa-based milk substitute. Int. J. Food Microbiol., 286: 31-36.https://doi.org /10.1016/j.ijfoodmicro.2018.07.013

Kundu P, Dhankhar J, Sharma A 2018. Development of non dairy milk alternative using soymilk and almond milk. Curr. Res. Nutr. Food Sci. J, 6: 203-210

Lai L-R, Hsieh S-C, Huang H-Y, Chou C-C 2013. Effect of lactic fermentation on the total phenolic, saponin and phytic acid contents as well as anti-colon cancer cell proliferation activity of soymilk. Journal of Bioscience and Bioengineering, 115: 552-556.https://doi.org/10.1016/j.jbiosc.2012.11.022

Mäkinen OE, Uniacke-Lowe T, O'Mahony JA, Arendt EK 2015. Physicochemical and acid gelation properties of commercial UHT-treated plant-based milk substitutes and lactose free bovine milk. Food Chem., 168: 630638.https://doi.org/10.1016/j.foodchem.2014.07.036

McClements DJ, Newman E, McClements IF 2019. Plant-based Milks: A Review of the Science Underpinning Their Design, Fabrication, and Performance. Compr. Rev. Food Sci. Food Saf., 18: 2047-2067.10.1111/1541-4337.12505 
Naziri E, Koupantsis T, Mantzouridou FT, Paraskevopoulou A, Tsimidou MZ, Kiosseoglou V 2017. Influence of thermal treatment on the stability of vegetable "milk" obtained by ultrafiltration of aqueous oil body extracts from various sources. Eur. J Lipid Sci. Tech., 119.10.1002/ejlt.201600362

Pineli LdLdO, Botelho RBA, Zandonadi RP, Solorzano JL, de Oliveira GT, Reis CEG, Teixeira DdS 2015. Low glycemic index and increased protein content in a novel quinoa milk. LWT, 63: 1261-1267.https://doi.org/10.1016/j.lwt.2015.03.094

Rincon L, Braz Assunção Botelho R, de Alencar ER 2020. Development of novel plant-based milk based on chickpea and coconut. LWT, 128: 109479.https://doi.org/10.1016/ j.lwt.2020.109479
Scholz-Ahrens KE, Ahrens F, Barth CA 2020. Nutritional and health attributes of milk and milk imitations. Eur. J. Nutr., 59: 19-34.10.1007/s00394-019-01936-3

Sethi S, Tyagi SK, Anurag RK 2016. Plant-based milk alternatives an emerging segment of functional beverages: a review. J. Food Sci. Tech., 53: 3408-3423

Tontul I, Topuz A 2018. Production of pomegranate fruit leather (pestil) using different hydrocolloid mixtures: An optimization study by mixture design. J. Food Process Eng., 41: e12657.10.1111/jfpe.12657 